\title{
Production of NO by Galactic Cosmic Rays and Lightning
}

\author{
Keith E. Grant ana Donald J. Wuebbles UCID--21145
}

DE87 014613

As part of the ongoing development of the LLNL 2-D Stratospheric Transport-Kinetics Model, values for NO production rates due to galactic cosmic rays (GCRs) and lightning have been calculated. Inclusion of these sources of $N O$ have been prompted by discrepancies between model results and satellite observations for $\mathrm{NO}_{y}\left(\mathrm{~N}, \mathrm{NO} . \mathrm{NO}_{2}, \mathrm{NO}_{3}, \mathrm{~N}_{2} \mathrm{O}_{5}, \mathrm{HNO}_{2}\right.$, $\mathrm{HO}_{2} \mathrm{NO}_{2}, \mathrm{HNO}_{3}, \mathrm{ClNO}$ ) in the lower stratosphere. These , screpancies, with model predicted mixing ratios being lower than observations, are not $u_{4}$ jue to the LLNL model (Ko et al, 1986; WMO, 1985), and suggest the need for sources of $\mathrm{NO}$ in addition to oxidation of $\mathrm{N}_{2} \mathrm{O}$ by $\mathrm{O}\left({ }^{1} \mathrm{D}\right)$.

The likclihood of GCRs as a source stratospheric odd nitroger. was noted in a brief report by Warneck (1972). Nicolet (1975) has given detailed NO production rates from this source as a function of altitude and geomagnetic latitude. Since the rate of GCRs entering the atmosphere is negatively modulated by solar activity, which varies over an 11 year cycle, values were given by Nicolet for both minimum and maxir: um NO production rates. Later authors have augmented this data by providing more ac urate estimates of the production yield of NO per ion pair (Frederick, 1976; Porter et al, 1.76 ; Jackman et al, 1979). These authors have recommended increasing Nicolet's estimate c one NO molecule per ion pair to 1.2-1.3 molecules per ion pair.

The suggestion of lightning as a source of NO has a long and rich history in the literature. Only a small fraction of this history will be discussed here, but much further detail and many more references are available from the works cited. Combining results from both a theoreticai shock wave model and laboratory measurements, Chameides et al (1977) have estimated the production of $\mathrm{NO}_{x}$ by lightning to be about $6 \times 10^{16}$ molecules $\cdot \mathrm{J}^{-1}$ of energy discharged. They estimate about $2 \times 10^{9} \mathrm{~J}$ per flash, and about 400 flashes per second globally, yielding an approximate global dissipation rate of $8 \times 10^{11} \mathrm{~W}$.

Griffing (1977) estimates an NO production efficiency factor varying between $4 \times 10^{16}$ and $6 \times 10^{10}$ molecules $\cdot J^{-1}$, depending on the degree of ionization produced, and an average energy of about $3 \times 10^{9} \mathrm{~J}$ per per flash. Given the physical uncertainties involved, these estimates are extremely close to those of Chameides (1977)

Borucki and Chameides (1984) have provided a detailed review of existing data and literature on $\mathrm{NO}$ production rates by lightning. By including a consideration of the reduced energy in strokes subsequent to the first in a single flash, they have concluded the total flash energy is approximately 1.75 times the energy of the first return stroke. With this inclusion, they conclude that the energy per flash is $4 \times 10^{8} \mathrm{~J}$ with an uncertainty factor of 2.5. Using data from satellite observations, they estimate a global Aashing rate of 100 flashes $\cdot s^{-1}$, a factor of four reduction from that estimated by Chameides et al (1977). These values for the global flash rate and energy per flash result in an estimate for the global dissipation rate ranging between $1.3 \times 10^{10}$ and $12 \times 10^{10} \mathrm{~W}$. They estimate an efficiency factor for NO production of about $9 \times 10^{16}$ molecules $\cdot \mathrm{J}^{-1}$. With the lowered estimate for the flashing rate, this range would include the estimate of Chameides et al 
(1977) given above. Lsing the values given for the global dissipation rate and chemical yield, Borucki and Chameides obtain a global nitrogen fixation rate of $2.6 \times 10^{9} \mathrm{~kg} \mathrm{~N}$ - $\mathrm{yr}^{-1}$. They caution, however that the actual value could range letween $0.8 \times 10^{9} \mathrm{~kg}$ $\mathrm{N} \cdot \mathrm{yr}^{-1}$ and $8.0 \times 109 \mathrm{~kg} \mathrm{~N} \cdot \mathrm{yr}^{-1}$.

Logan (1983) has also presented a review of tropospheric $\mathrm{NO}_{z}$ budgets containing a useful discussion of various sources of data for production of $\mathrm{NO}_{x}$ by lightning and the relevant uncertainties involved.

Ko et al (1986) have investigated the effect of including lightning produced $\mathrm{NO}_{z}$ in their model. Based on data including that reviewed above, they have utilized four separate source models. Their $\mathrm{H} 2$ and $\mathrm{H} 4$ models contribute sources of $2 \times 10^{9} \mathrm{~kg} \mathrm{~N}_{\mathrm{gr}}{ }^{-1}$ and $4 \times$ $10^{9} \mathrm{~kg} \mathrm{~N} \cdot \mathrm{yr}^{-1}$ uniformly distributed between $30^{\circ} \mathrm{N}$ and $30^{\circ} \mathrm{S}$ latitudes and between altitudes of $4 \mathrm{~km}$ to $15 \mathrm{~km}$. These models correspond to source strengths of $1 \times 10^{3} \mathrm{~cm}^{-1} \cdot \mathrm{s}^{-1}$ and 2 $\times 10^{3} \mathrm{~cm}^{-1} \cdot \mathrm{s}^{-1}$ respectively. Models L2 and L4 had the same respective source strengths, but were restricted to altitudes of $4 \mathrm{~km}$ to $11 \mathrm{~km}$. All four models are well within the range for global source rates given by Borucki and Chameides (1984). The confinement of the sources to the tropical region was based both on geographical dependence of lightning flash frequency and consideration of the region where upward transport of $\mathrm{NO}_{2}$ across the tropopause would be expected.

Jackman et al (1980) have provided an intercomparison of source strength for NO. including production by GCRs and lightning. They note that GCRs produce NO mostly below $40 \mathrm{~km}$, with lightning producing NO only below the tropopause. They also note that annual production of NO by GCRs integrated over latitudes above $50^{\circ}$ varies between 1.1-1.6 $\times 10^{33}$ molecules while production in this region by $\mathrm{N}_{2} \mathrm{O}$ oxidation is $1.4 \times 10^{33}$. They also caution, however, that because on a global scale GCR production rates are at least an order of magnitude smaller than the $\mathrm{N}_{2} \mathrm{O}$ oxidation source, transport processes can greatly affect the relative importance of different sources.

Jackman et al (1980) have also reviewed the literature on solar proton events (SPEs) as a source of $\mathrm{NO}$ at latitudes above $50^{\circ}$. Due to their inherently short-lived, episodic, and hence unpredictable nature, this source of NO has not been included in the LLNL model. SPEs are probably not important to annual $\mathrm{NO}_{x}$ budgets except for studies of these episodic events.

\section{Method}

Values for production of NO by galartic cosmic rays (GCRs) as a function of latitude and altitude were taken from Nicolet (1975). The data as published, were on several grids giving the production of $\mathrm{NO}$ as a function of altitude and geomagnetic latitude. The separate grids approximately corresponded to regions of low, middle, and high altitudes. Each such grid appears to have been chosen to show the variation in NO production rates with latitude and altitude using the minimum number of points adequate for the region covered.

To make the data more convenient to utiize, all of the data were first placed on the geomagnetic latitude grid originally used for middle altitud. $\_$a. This grid was chosen because, being in a region where NO production was varying the fastest as a function 


\section{DISCLAIMER}

This report was prepared as an account of work sponsored by an agency of the United States Government. Neither the United States Government nor any agency thereof, nor any of their employees, makes any warranty, express or implied, or assumes any legal liability or responsibility for the accuracy, completeness, or usefulness of any information, apparatus, product, or process disclosed, or represents that its use would not infringe privately owned rights. Reference herein to any specific commercial product, process, or service by trade name, trademark, manufacturer, or otherwise does not necessarily constitute or imply its endorsement, recommendation, or favoring by the United States Government or any agency thereof. The views and opinions of authors expressed berein do not necessarily state or feflect those of the United States Government or any agency thercor. 
of latitude, it was a superset of the other grids used. For the middle altitude region, srecifically at altitudes of $10,12.5,15,17.5,20,22.5,25,27.5,30,35$, and 40 kilometers, data were given by Nicolet (1975) at geomagnetic latitudes of $0^{\circ}, 10^{\circ}, 15^{\circ}, 20^{\circ}, 25^{\circ}, 30^{\circ}$, $35^{\circ}, 40^{\circ}, 45^{\circ}, 50^{\circ}, 55^{\circ}$, and $60^{\circ}$. For the interpolations described below, the $60^{\circ}$ values were treated as being valid for specific points at $60^{\circ}$ and $90^{\circ}$.

Because of a lack of other low altitude data, data given for $0 \mathrm{~km}$ to $10 \mathrm{~km}$ and latitudes greater than or equal to $44^{\circ}$ during minimum $N O$ production and for $5 \mathrm{~km}$ to $10 \mathrm{~km}$ and latitudes greater than or equal to $45^{\circ}$ for average production of NO were used as a basis for extrapolating the NO production values below $10 \mathrm{~km}$ at all latitudes. Scale factors were derived from these data, relative to the production rate at $10 \mathrm{~km}$. These scale factors, which are shown in Table 1, were then applied as a single relative profile at all latitudes.

In the "high altitude grid", data were given by Nicolet (1975) for altitudes of $35.0,40.0$, $45.0,50.0,55.0$, and 60.0 kilometers at geomagnet ic latitudes of $0^{\circ}, 15^{\circ} .30^{\circ}, 40^{\circ}, 50^{\circ}, 60^{\circ}$, and $70^{\circ}$. These production rates were linearly interpolated as a function of sine-latitude to the latitude grid for mid-altitude data given above.

The above process of producing NO production rate data on a uniform geometric grid was initially done for both minimum and maximum production rate data. Following collection and interpolation to a single grid, these data were averaged and differenced to convert to tables for average production and amplitude of variation (over a solar cycle). A scaling factor of 1.27 was then applied to these data, as recommended by Porter et al (1976) and Jackman et al (1979), to account for a higher production per ion pair than was used by Nicolet (1975). The resulting data are shown in Tables 2 and 3 as functions of altitude and sine of geomagnetic latitude.

To interpolate the average production rates (Table 2) to the (altitude, sine of geographic latitude) grid used by the LLNL 2-D model, the data were averaged around geographic latitude bands using 10 increments in longitude. For each of the $\mathbf{3 6}$ points in the zonal band, the corresponding geomagnetic latitude was calculated, following which an area weighted interpolation was made from the data in Table 2. The resulting rates on the LLNL 2-D model grid of NO production due to GCRs are shown in Table 4.

To include the production zate of NO by lightning, we used the H2 model described by Ko et al. (1986). This model uses a uniform production rate of 1000 molecules $\cdot \mathrm{cm}^{-3} \cdot \mathrm{s}^{-1}$ between $30^{\circ}$ latitude and between $4-15 \mathrm{~km}$ altitude, resulting in a total source of $2 \times$ $10^{9} \mathrm{~kg} \mathrm{~N} \cdot \mathrm{yr}^{-1}$. The total source strength with this source added to the GCR production is shown in Table 5 .

\section{Comparison with LIMS data and predictions from other models}

With the combined NO production rates from GCRs and lighining included in the LLNL 2-D model, we compared our predicted $\mathrm{NO}_{y}$ mixing ratios with those from LIMS (Limb Infrared Monitor of the Stratosphere) data and other models (WMO, 1985). Graphs of $\mathrm{NO}_{y}$ mixing ratios versus latitude are shown in Figure 1 for pressure altitudes of $30 \mathrm{mb}$, $16 \mathrm{mb}$, and $3 \mathrm{mb}$. Although our predicted $\mathrm{NO}_{y}$ mixing ratios are lower than the LIMS data at $16 \mathrm{mb}$ and $30 \mathrm{mb}$, our values at these pressures are generally higher and in better agreement with LIMS than are the corresponding mixing ratios from the other models 
shown. At $3 \mathrm{mb}$, both our results and those of Garcia and Solomon are somewhat higher than the mixing ratios from LIMS. Further research is needed on the sensitivity of these results to changes in model transport processes. 


\section{References}

Borucki, William J., and William L. Chameides, 1984: "Lightning: Estimates of the Rates of Energy Dissipation and Nitrogen Fixation", Rev. Geophys. \& Space. Phys., 22 (4), 363-372.

Chameides, W.L., D.H. Stedman, R.R. Dickerson, D.W. Rusch, and R.J.Cicerone, 1977: "NOx Production in Lightning", J. Atmos. Sci., 34, 143-149.

Frederick, John E., 1976: "Solar Corpuscular Emission and Neutral Chemistry in the Earth's Middle Atmosphere", J. Geophys. Hes., 81 (10), 3179-3186.

Griffing, George W., 1977: "Ozone and Oxides of Nitrogen Production During Thunderstorms", J. Geophys. Res., $82(6), 943-950$.

Jackman, C.H., H.S. Porter, J.E. Frederick, 1979: "Upper Limits on Production Rate of NO per Ion pair", Nature, 280, 170.

Jackman, C.H., J.E. Frederick, and R.S. Stolarski, 1980: "Production of Odd Nitrogen in the Stratosphere and Mesosphere: As Intercomparison of Source Strengths", $J$, Geophys. Res., 85 (C12), 7495-7505.

Ko, Malcolm K.W., Michael B. McElroy, Debra K. Weisenstein, and Nien Dak Sze, 1986: "Lightning: A Possible Source of Stratospheric Odd Nitrogen", J. Geophys. Res., gI (D5), 5395-5404.

Logan, Jennifer A., 1983: "Nitrogen Oxides in the Troposphere: Global and Regional Budgets", J. Geophys. Res., 88 (C15), 10,785-10,807.

Nicolet, Marcel, 1975: "On the Production of Nitric Oxide by Cosmic Rays in the Mesosphere and Stratosphere", Planet. Space Sei, 29, 637-649.

Porter, H.S., C.H. Jackman, and A.E.S. Green, 1976: "Éfíciencies for Production of Atomic Nitrogen and Oxygen by Relativistic Proton Impact in Air", J. Chem. Phys., $65(1), 154-167$.

Warneck, Peter, 1972: "Cosmic Radiation as a Source of Odd Nitrogen in the Stratosphere", J. Geophys. Res., 77, 6589-6591.

WMO (World Meteorological Organization), 1985: Atmospheric Ozone 1985, Global Ozone Research and Monitoring Project, Report No. 16, Vol. II, Ch. 10.

This work was performed under the ausplees of the U.S. Department of Energy by Lawrence Livermore National Laboratory under contract No. W-7405-Eng-48. 
Tuble 1: NO production rate scale factors below $10 \mathrm{~km}$ relative to the $10 \mathrm{kr}$ production rate.

$\begin{array}{ll}\text { Alt } & \text { Scale } \\ 0.0 & 0.0992 \\ 1.0 & 0.1260 \\ 2.0 & 0.1603 \\ 3.0 & 0.2023 \\ 4.0 & 0.2672 \\ 5.0 & 0.3562 \\ 6.0 & 0.4589 \\ 7.0 & 0.5719 \\ 8.0 & 0.7226 \\ 9.0 & 0.8699\end{array}$

Table 2: Average (over a solar cycle) production of NO by galactic cosmic rays $\left(\mathrm{cm}^{-3} \mathrm{~s}^{-1}\right)$. Given on an altitude (km) by sin(geomagnetic latitude) grid.

\begin{tabular}{|c|c|c|c|c|c|c|c|c|c|c|c|c|}
\hline $\mathrm{km} / \mathrm{lat}$ & .0000 & .1736 & .2588 & .3420 & .4226 & .5000 & .5736 & .6428 & .7071 & .7660 & .8192 & .8660 \\
\hline .00 & 1.68 & 1.80 & 1.96 & 2.19 & 2.42 & 2.63 & 2.82 & 3.17 & 3.45 & 3.67 & 3.74 & 4.13 \\
\hline 1.00 & 2.12 & 2.28 & 2.48 & 2.77 & 3.06 & 3.32 & 3.57 & 4.01 & 4.37 & 4.64 & 4.73 & 5.21 \\
\hline 2.00 & 2.68 & 2.89 & 3.14 & 3.51 & 3.88 & 4.21 & 4.52 & 5.08 & 5.53 & 5.88 & 5.99 & 6.61 \\
\hline 3.00 & 3.37 & 3.63 & 3.94 & 4.41 & 4.88 & 5.29 & 5.68 & 6.38 & 6.96 & 7.38 & 7.53 & 8.31 \\
\hline 4.00 & 4.44 & 4.78 & 5.19 & 5.80 & 6.42 & 6.96 & 7.48 & 8.40 & 9.15 & 9.71 & 9.90 & 10.92 \\
\hline 5.00 & 5.88 & 6.33 & 6.88 & 7.69 & 8.50 & 9.23 & 9.91 & 11.13 & 12.12 & 12.87 & 13.12 & 14.47 \\
\hline 6.00 & 7.58 & 8.16 & 8.86 & 9.91 & 10.96 & 11.89 & 12.76 & 14.34 & 15.62 & 16.58 & 16.90 & 18.65 \\
\hline 7.00 & 9.44 & 10.17 & 11.04 & 12.35 & 13.66 & 14.82 & 15.91 & 37 & 19.47 & 6 & 21.06 & 23.24 \\
\hline 8.00 & 11.93 & 12.85 & 13.95 & 15.60 & 17.25 & 18.72 & 20.10 & 22.58 & 24.59 & 26.11 & 25.61 & 29.37 \\
\hline 9.00 & 14.36 & 15.47 & 16.79 & 18.78 & 20.77 & 22.54 & 24.19 & 27.18 & 29.61 & 31.43 & 32.04 & 35.35 \\
\hline 10.00 & 16.51 & 17.78 & 19.30 & 21.59 & 23.88 & 25.91 & 27.81 & 31.24 & 34.04 & 36.13 & 36.83 & 40.64 \\
\hline 12.50 & 17.78 & 19.05 & 20.45 & 22.10 & 24.64 & 28.07 & 33.34 & 34.48 & 38.29 & 42.16 & 44.01 & 49.91 \\
\hline 15.00 & 13.34 & 14.60 & 15.49 & 17.15 & 19.43 & 21.97 & 25.08 & 29. & 33.46 & & 40.01 & 47.63 \\
\hline 17.50 & 9.52 & 10.16 & 10.80 & 12.06 & 13.46 & 15.62 & 18.10 & 21.65 & 25.27 & 29.21 & 31.81 & 39.62 \\
\hline 20.00 & 6.35 & 6.60 & 6.86 & 7.62 & 8.76 & 10.16 & 11.62 & 14.35 & 17.27 & 20.51 & 23.18 & 29.46 \\
\hline 22.50 & 3.43 & 3.56 & 3.94 & 4.57 & 5.33 & 6.22 & 7.11 & 8.76 & 10.80 & 13 & 15.75 & 21.21 \\
\hline 25.00 & 2.16 & 2.29 & 2.41 & 2.79 & 3.17 & 3.94 & 4.25 & 5.40 & 7.05 & 8.83 & 10.67 & 14.73 \\
\hline 27.50 & 1.27 & 1.27 & 1.40 & 1.65 & 2.03 & 2.41 & 2.73 & 3.56 & 4.64 & 5.78 & 6.92 & 10.16 \\
\hline 30.00 & 1.27 & 1.27 & 1.27 & 1.27 & 1.27 & 1.40 & 1.65 & 2.29 & 2.98 & 3.68 & 4.51 & 6.86 \\
\hline 35.00 & .39 & .42 & .43 & .53 & .62 & .71 & .93 & 1.14 & 1.61 & 2.03 & 2.50 & 2.92 \\
\hline 40.00 & .19 & .21 & .22 & .26 & .31 & .36 & .46 & .56 & .79 & 1.01 & 1.23 & 1.42 \\
\hline 45.00 & .10 & .11 & .11 & .14 & .16 & .18 & .24 & .29 & .42 & .53 & .65 & .75 \\
\hline 50.00 & .05 & .06 & .06 & .08 & .09 & .10 & .13 & .15 & .22 & .29 & .35 & .41 \\
\hline 55.00 & .03 & .03 & .04 & .04 & .05 & .05 & .07 & .09 & .12 & .15 & .19 & .22 \\
\hline 60.00 & .01 & .02 & .03 & .03 & .03 & .113 & .03 & . $1 \mathrm{H}$ & .06 & .09 & .11 & .13 \\
\hline
\end{tabular}


Table 3: Amplitude of variation (over a solar cycle) production of NO by galactic cosmic rays (cm-3s-1). Given or an altitude (km) by sin(geomagnetic latitude) grid.

\begin{tabular}{|c|c|c|c|c|c|c|c|c|c|c|c|c|}
\hline $\mathrm{km} / \mathrm{lat}$ & 0000 & .1736 & .2588 & .3420 & .4226 & .5000 & .5736 & .6428 & .7071 & .7660 & .8192 & .8660 \\
\hline .00 & .00 & .00 & .00 & .00 & .00 & .00 & .12 & .08 & .10 & .32 & .39 & .00 \\
\hline 1.00 & .00 & .00 & .00 & .00 & .00 & .00 & .15 & .10 & .13 & .40 & .49 & .00 \\
\hline 2.00 & .00 & .00 & .00 & .00 & .00 & .00 & .19 & .12 & .17 & .51 & .62 & .00 \\
\hline 3.00 & .00 & .00 & .00 & .00 & .00 & .00 & .23 & .16 & .21 & .64 & .78 & .00 \\
\hline 4.00 & .00 & .00 & .00 & .00 & .00 & .00 & .31 & .20 & .27 & .84 & 1.02 & .00 \\
\hline 5.00 & .00 & .60 & .00 & .00 & .00 & .00 & .41 & .27 & .36 & 1.11 & 1.36 & .00 \\
\hline 6.00 & .00 & .00 & .00 & .00 & .00 & .00 & .52 & .35 & .47 & 1.43 & 1.75 & .00 \\
\hline 7.00 & .00 & .00 & .00 & .00 & .00 & .00 & .65 & .44 & .58 & 1.78 & 2.18 & .00 \\
\hline 8.00 & .00 & .00 & .00 & .00 & .00 & .00 & .83 & .55 & .73 & 2.25 & 2.75 & .00 \\
\hline 9.00 & .00 & .00 & .00 & .00 & .00 & .00 & .99 & .66 & .88 & 2.71 & 3.31 & .00 \\
\hline 10.00 & .00 & .00 & .00 & .00 & .00 & .00 & 1.14 & .76 & 1.02 & 3.11 & 3.81 & .00 \\
\hline 12.50 & .00 & .00 & .00 & .00 & .00 & .00 & -1.59 & 2.35 & 2.48 & 3.43 & 5.27 & .00 \\
\hline 15.00 & .00 & .00 & .00 & .00 & .00 & .00 & 1.97 & 2.60 & 2.73 & 3.17 & 5.72 & .00 \\
\hline 17.50 & .00 & .00 & .00 & .00 & .00 & .00 & 1.21 & 1.59 & 2.16 & 3.05 & 4.89 & .00 \\
\hline 20.00 & .00 & .00 & .00 & .00 & .00 & .00 & 1.21 & 1.40 & 1.78 & 2.48 & 3.49 & .00 \\
\hline 22.50 & .00 & .00 & .00 & .00 & .00 & .00 & .76 & .89 & 1.65 & 2.03 & 2.92 & .00 \\
\hline 25.00 & .00 & .00 & .00 & .00 & .00 & .00 & .32 & .44 & .83 & 1.33 & 2.03 & .00 \\
\hline 27.50 & .00 & .00 & .00 & .00 & .00 & .00 & .32 & .38 & .57 & .95 & 1.21 & .00 \\
\hline 30.00 & .00 & .00 & .00 & .00 & .00 & .00 & .25 & .25 & .32 & .38 & .70 & .00 \\
\hline 35.00 & .00 & .00 & .00 & .00 & .00 & .00 & .00 & .00 & .20 & .38 & .72 & 1.02 \\
\hline 40.00 & .00 & .00 & .00 & .00 & .00 & .00 & .00 & .00 & .09 & .17 & .34 & .48 \\
\hline 45.00 & .00 & .00 & .00 & .00 & .00 & .00 & .00 & .00 & .05 & .09 & .18 & .25 \\
\hline 50.00 & .00 & .00 & .00 & .00 & .00 & .00 & .00 & .00 & .02 & .04 & .10 & .14 \\
\hline 55.00 & .00 & .00 & .00 & .00 & .00 & .00 & .00 & .00 & .01 & .03 & .05 & .08 \\
\hline 60.00 & .00 & .00 & .00 & .00 & .00 & .00 & .00 & .00 & .01 & .01 & .03 & .04 \\
\hline
\end{tabular}


Table 4: Average (over a solar cycle) production of NO by galactic cosmic rays (cm-3s-1). Given on the altitude (km) by sin(latitude) grid used by the LLNL 2-D model.

\begin{tabular}{|c|c|c|c|c|c|c|c|c|}
\hline $\mathrm{kra} / \mathrm{lat}$ & $-.98 \tilde{5}$ & -.945 & .885 & -.800 & -.675 & -.500 & -.300 & -.100 \\
\hline 11.5 & 5.91 & 5.90 & 5.64 & 5.31 & 4.59 & 3.78 & 3.02 & 2.61 \\
\hline 24.5 & 12.70 & 12.68 & 12.12 & 11.41 & 9.86 & 8.12 & 6.49 & 5.60 \\
\hline 37.5 & 26.30 & 26.27 & 25.11 & 23.64 & 20.43 & 16.82 & 13.43 & 11.59 \\
\hline 410.5 & 42.49 & 42.44 & 40.41 & 37.81 & 32.53 & 26.40 & 20.99 & 18.15 \\
\hline $\begin{array}{lll}5 & 13.5\end{array}$ & 49.00 & 48.91 & 45.63 & 41.39 & 34.11 & 25.88 & 19.96 & 17.26 \\
\hline 616.5 & 42.82 & $A \approx .72$ & 38.85 & 34.20 & 26.11 & 18.77 & 13.93 & 11.91 \\
\hline 719.5 & 31.50 & 31.41 & 28.02 & 23.91 & 17.22 & 11.69 & 8.53 & 7.34 \\
\hline 822.5 & 21.21 & 21.13 & 18.27 & 14.96 & 10.01 & 6.43 & 4.47 & 3.66 \\
\hline 925.5 & 13.82 & 13.76 & 11.74 & 9.43 & 6.01 & 3.65 & 2.55 & 2.10 \\
\hline 10285 & 8.84 & 8.80 & 7.35 & 5.86 & 3.57 & 2.16 & 1.51 & 1.30 \\
\hline 11315 & 5.68 & 5.65 & 4.74 & 3.78 & 2.28 & 1.38 & 1.06 & 1.01 \\
\hline 12345 & 3.31 & 3.31 & $2 \cdot 3$ & 2.39 & 1.56 & .88 & .59 & .50 \\
\hline 13375 & 2.17 & 2.17 & $1.9 \%$ & 1.61 & 1.07 & .59 & .39 & .31 \\
\hline 14405 & 1.36 & 1.35 & 1.23 & 1.01 & .68 & .37 & .24 & .20 \\
\hline 15435 & .95 & .95 & .87 & .71 & .47 & .26 & .17 & .14 \\
\hline 16465 & .65 & .65 & .59 & .48 & .32 & .18 & .11 & .09 \\
\hline 17495 & .44 & .44 & .40 & .33 & .22 & .12 & .08 & .06 \\
\hline 18525 & .31 & .31 & .28 & .23 & .15 & .09 & .06 & .05 \\
\hline $\mathrm{km} / \mathrm{lat}$ & .100 & .300 & .500 & .675 & .800 & .885 & .945 & .985 \\
\hline 11.5 & 2.62 & 3.05 & 3.80 & 4.64 & 5.34 & 5.67 & 5.91 & 5.91 \\
\hline 24.5 & 5.62 & 6.56 & 8.17 & 9.97 & 11.48 & 12.19 & 12.69 & 12.70 \\
\hline 37.5 & 11.65 & 13.58 & 16.92 & 20.65 & 23.78 & 25.25 & 26.29 & 26.30 \\
\hline 410.5 & 18.23 & 21.21 & 26.63 & 32.86 & 38.05 & 40.65 & 42.47 & 42.49 \\
\hline 513.5 & 17.35 & 20.12 & 26.32 & 34.43 & 41.82 & 45.99 & 48.97 & 49.00 \\
\hline 616.5 & 11.98 & 14.05 & 19.00 & 26.52 & 34.70 & 39.28 & 42.79 & 42.82 \\
\hline 719.5 & 7.37 & 8.60 & 11.83 & 17.54 & 24.37 & 28.38 & 31.46 & 31.50 \\
\hline 822.5 & 3.67 & 4.53 & 6.50 & 10.20 & 15.35 & 18.56 & 21.18 & 21.21 \\
\hline 925.5 & 2.11 & 2.58 & 3.70 & 6.16 & 9.70 & 11.95 & 13.80 & 13.82 \\
\hline 10285 & 1.30 & 1.52 & 2.18 & 3.66 & 6.03 & 7.50 & 8.83 & 8.84 \\
\hline 11315 & 1.02 & 1.06 & 1.40 & 2.34 & 3.89 & 4.84 & 5.67 & 5.68 \\
\hline 12345 & .51 & .60 & .90 & 1.60 & 2.45 & 2.97 & $3.2 !$ & 3.31 \\
\hline 13375 & .31 & .39 & .61 & 1.10 & 1.65 & 1.98 & 2.17 & 2.17 \\
\hline 14405 & .20 & .25 & .38 & .69 & 1.03 & 1.24 & 1.35 & 1.36 \\
\hline 15435 & .14 & .17 & .27 & .48 & .72 & .87 & .95 & .95 \\
\hline 16465 & .09 & .12 & .18 & .33 & .49 & .59 & .65 & .65 \\
\hline 17495 & .06 & .08 & .12 & .22 & .33 & .40 & .44 & .44 \\
\hline 1852 & .05 & .06 & 09 & .16 & .24 & .28 & .31 & .31 \\
\hline
\end{tabular}


Table 5: A verage (over a solar cycle) production of NO by galartic cosmic rays plus NO production by lightning $(\mathrm{cm}-3 \mathrm{~s}-1)$. Given on the altitude $(\mathrm{km})$ by $\sin ($ latitude) grid used by the LLNL 2-D model.

\begin{tabular}{|c|c|c|c|c|c|c|c|c|}
\hline $\mathrm{km} / \mathrm{lat}$ & -.985 & -.945 & -.885 & -.800 & .675 & $\cdots .500$ & -.300 & -.100 \\
\hline 11.5 & 5.91 & 5.90 & 5.64 & 5.31 & 4.59 & 3.78 & 3.02 & 2.61 \\
\hline 24.5 & 12.70 & 12.68 & 12.12 & 11.41 & 9.86 & 363.68 & 673.15 & 672.26 \\
\hline 37.5 & 26.30 & 26.27 & 25.11 & 23.64 & 20.43 & 550.15 & 1013.43 & 1011.59 \\
\hline 410.5 & 42.49 & 42.44 & 40.41 & 37.81 & 32.53 & 559.74 & 102099 & 1018.15 \\
\hline 513.5 & 49.00 & 48.91 & 45.63 & 41.39 & 34.11 & 559.22 & 1019.96 & 101726 \\
\hline 616.5 & 42.82 & 42.72 & 38.85 & 34.20 & 26.11 & 18.77 & 13.93 & 11.91 \\
\hline 719.5 & 31.50 & 31.41 & 23.02 & 23.91 & 17.22 & 11.69 & 8.53 & 7.94 \\
\hline 822.5 & 21.21 & 21.13 & 18.27 & 14.96 & 10.01 & 6.43 & 4.47 & 3.66 \\
\hline 925.5 & 13.82 & 13.76 & 11.74 & 9.43 & 6.91 & 3.65 & 2.55 & 2.10 \\
\hline 10285 & B.84 & 8.80 & 7.35 & 5.86 & 3.57 & 2.16 & 1.51 & 1.30 \\
\hline 11315 & 5.68 & 5.65 & 4.74 & 3.78 & 2.28 & 1.38 & 1.06 & 1.01 \\
\hline 12345 & 3.31 & 3.31 & 2.94 & 2.39 & 1.56 & .88 & .59 & .50 \\
\hline 13375 & 2.17 & 2.17 & 1.97 & 1.61 & 1.07 & .59 & .39 & .31 \\
\hline 14405 & 1.36 & 1.35 & 1.23 & 1.01 & .68 & .37 & .24 & .20 \\
\hline 15435 & .95 & .95 & .87 & .71 & .47 & .26 & .17 & .14 \\
\hline 16465 & .65 & .65 & .59 & .48 & .32 & .18 & .11 & .09 \\
\hline 17495 & .44 & .44 & .40 & .33 & .22 & .12 & .08 & .06 \\
\hline 18525 & .31 & .31 & .28 & .23 & .15 & .09 & .06 & .05 \\
\hline $\mathrm{km} / \mathrm{lat}$ & .100 & .300 & .500 & .675 & 800 & .885 & .945 & .985 \\
\hline 11.5 & 2.62 & 3.05 & 3.80 & 4.64 & 5.34 & 5.67 & 5.91 & 5.91 \\
\hline 24.5 & 672.29 & 673.22 & 363.72 & 9.97 & 11.48 & 12.19 & 12.69 & 12.70 \\
\hline 37.5 & 101165 & 1013.58 & 550.25 & 20.65 & 23.78 & 25.25 & 26.29 & 26.30 \\
\hline 410.5 & 101823 & 1021.21 & 559.97 & 32.86 & 38.05 & 40.65 & 42.47 & 42.49 \\
\hline $5 \quad 13.5$ & 101735 & 1020.12 & 559.65 & 34.43 & 41.82 & 45.99 & 48.97 & 49.00 \\
\hline 616.5 & 11.98 & 14.05 & 19.00 & 26.52 & 34.70 & 39.28 & 42.79 & 42.82 \\
\hline 719.5 & 7.37 & 8.60 & 11.83 & 17.54 & 24.37 & 28.38 & 31.46 & 31.50 \\
\hline 822.5 & 3.67 & 4.53 & 6.50 & 10.20 & 15.35 & 18.56 & 21.18 & 21.21 \\
\hline 925.5 & 2.11 & 2.58 & 3.70 & 6.16 & 9.70 & 11.95 & 13.80 & 13.82 \\
\hline 10285 & 1.30 & 1.52 & 2.18 & 3.66 & 6.03 & 7.50 & 8.83 & 8.84 \\
\hline 11315 & 1.02 & 1.06 & 1.40 & 2.34 & 3.89 & 4.84 & 5.67 & 5.68 \\
\hline 12345 & .51 & .60 & .90 & 1.60 & 2.45 & 2.97 & 3.31 & 3.31 \\
\hline 13375 & .31 & .39 & .61 & 1.10 & 1.65 & 1.98 & 2.17 & 2.17 \\
\hline 14405 & .20 & .25 & .38 & .69 & 1.03 & 1.24 & 1.35 & 1.36 \\
\hline 15435 & .14 & .17 & .27 & .48 & .72 & .87 & .95 & .95 \\
\hline 16465 & .09 & .12 & .18 & .33 & $.4 y$ & .59 & .65 & .65 \\
\hline 17496 & .06 & .08 & .12 & .22 & .33 & .40 & .44 & .44 \\
\hline 18525 & .05 & .06 & .09 & .16 & .24 & .28 & .31 & .31 \\
\hline
\end{tabular}



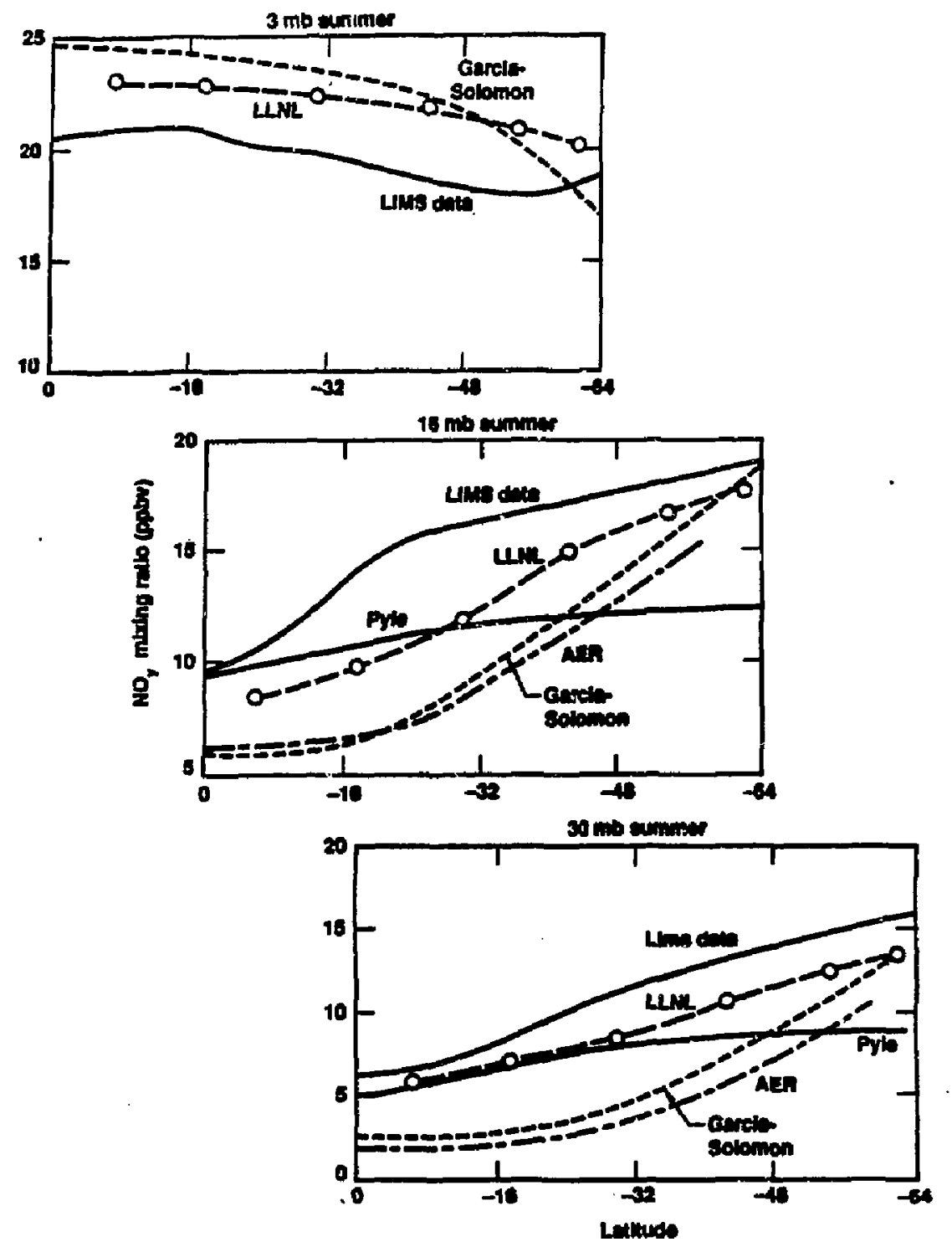

Figure 1. Model calculated mixing ratios of total odd nitrogen, NO $\mathrm{O}_{p}$ at $30, \mathbf{1 6}$, and 3 mb as compared with LMS data and several other models (adapted from WMO, 1985). 